\title{
Entre o Cuidado e a Autonomia: Deficiência visual e relações de ajuda
}

Olivia von der Weid ${ }^{\mathrm{a}}$

O artigo reflete sobre as relações de troca estabelecidas nos deslocamentos urbanos cotidianos de pessoas cegas a partir do imperativo da ajuda, com especial atenção para o cruzamento entre gênero e deficiência. Partindo do relato de pessoas cegas sobre suas experiências de serem ajudadas, especialmente no cenário da rua, avalio as condições da relação de troca que se estabelece em encontros deste tipo. A reflexão coloca situações etnográficas em diálogo com a forma como a dimensão da ajuda tem sido vista pelo care studies e disability studies. Sem perder de vista as noções de cuidado, dependência e autonomia que alimentam o debate entre as correntes, proponho um olhar para a forma como a dimensão localizada da ajuda é capaz de articular diferentes modos de agir e pensar a deficiência.

Deficiência, Cegueira, Mobilidade Urbana, Gênero, Cuidado.

Tomando como base as situações de dependência presentes nas relações entre deficientes e seus cuidadores, as teóricas feministas dos estudos sobre cuidado (care studies) criticam os ideais de autonomia, racionalidade e independência subjacentes à noção de sujeito ocidental argumentando que a vulnerabilidade e a dependência são aspectos constitutivos de todos os seres humanos. Ao longo da vida todos nós precisamos ser cuidados, seja na infância, no processo de envelheci-

a Professora do Departamento de Antropologia da Universidade Federal Fluminense (GAP/UFF). Email: oliviaweid@id.uff.br. 
mento ou em situações de maior fragilidade, como na doença ou na deficiência. Este seria um princípio ético e moral da própria condição humana. Buscando reabilitar práticas e valores que na vida social costumam permanecer implícitos ou são mesmo depreciados, as relações de dependência foram positivadas, consideradas fontes de uma experiência moral única, o cuidado, definido como uma espécie de atenção aos outros, preocupação com o seu bem-estar e as atividades concretas visando esse bem-estar (Kittay 1999; Diniz 2007).

Ao dar visibilidade à dimensão do cuidado como questão de justiça social busca-se politizar o contexto da vida privada e, ao mesmo tempo, resgatar a condição da mulher cuidadora. A questão do cuidado vira, então, uma questão de gênero, de reconhecimento e valorização de um trabalho realizado massivamente por mulheres e, em última instância, de transformação uma ordem social desigual e excludente, em que apenas algumas atividades de doação trazem honra e prestígio, enquanto outras, ainda que fundamentais para o funcionamento da vida social, são renegadas (Tronto 1999; Kittay 2011; Caillé 2014).

Embora a deficiência tenha servido de inspiração e lugar de atenção e pesquisa para os estudos sobre cuidado, suas ideias encontraram resistência de outra corrente de pensamento que se fortalece a partir do movimento social de pessoas com deficiência, o disability studies. Os estudos sobre deficiência se desenvolvem denunciando certas práticas e modos de organização das relações de cuidado, especialmente as que estavam presentes no contexto de institucionalização e medicalização de pessoas com deficiência. Enquanto as feministas do care studies viram as relações de cuidado pela função que ocupavam na construção dos papéis sociais de homens e mulheres ou, ainda, ressaltaram suas propriedades positivas, ainda que socialmente desvalorizadas, como generosidade, confiança, confidência, amor, compromisso, prazer e estima (Kittay 1999; Tronto 1999), os ativistas da deficiência o viram, primordialmente, pela infantilização e desempoderamento das pessoas com deficiência (Shakespeare 2000; Hughes et al. 2005). 
Ao invés de indivíduos física e funcionalmente mal ajustados à sociedade, os estudos sobre deficiência propõem a redefinição de suas experiências de vida como a de pessoas socialmente excluídas. A deficiência é reformulada como uma construção social que se origina nas barreiras econômicas, legais, culturais, atitudinais e arquitetônicas que a sociedade impõe às pessoas com deficiência, rejeitando-se a visão médica, até então predominante, que considerava a deficiência como resultado de um déficit corporal ou psíquico individual ${ }^{1}$. Fundando-se sobre uma visão negativa da dependência, os estudos sobre deficiência vem afirmando a capacidade de pessoas com deficiência fazerem escolhas e controlarem suas próprias vidas, o que se traduz no lema 'Nada Sobre Nós sem Nós', adotado pelo movimento no início dos anos 2000 (Sassaki 2007). Com isso, criticam a natureza normativa do corpo capaz, o padrão bio-funcional que os constitui, enquanto promovem a ideia de um sujeito autônomo, o único capaz de definir e avaliar os serviços que recebe e que, portanto, deve estar no controle dos serviços sem ser capturado pelos laços emocionais com os cuidadores. Como lembram Winance et al. (2015), esta demanda específica - a autonomia - associada à denúncia das relações de dominação até então sofridas nas práticas de cuidado, está no coração da luta do movimento de pessoas com deficiência.

$\mathrm{Na}$ comparação entre os argumentos pode-se identificar uma divergência em torno da noção de (in)dependência. A ética feminista do cuidado se baseia no reconhecimento da interdependência, das relações e responsabilidades mútuas, criticando noções de autonomia e independência por estarem enraizadas em uma visão moderna, masculina e individualista das pessoas. Já para o movimento de pessoas com deficiência, ao invés da noção de 'fazer tudo sozinho', independência significa ter controle sobre a assistência ou ajuda que lhes é necessária, e está mais próxima da noção de escolha ou autonomia. Para Paperman (2013), uma das principais contribuições da perspectiva dos estudos sobre deficiência para a noção de cuidado foi iluminar o caráter político da polarização entre cuidadores e destinatários de cui- 
dado, entre pessoas consideradas autônomas e aquelas que são vistas como dependentes ou vulneráveis. Considerar que qualquer pessoa que precise de ajuda com atividades físicas da vida diária é dependente seria uma atitude capacitista ${ }^{2}$.

Tendo em vista o debate acima esboçado proponho, neste artigo, uma reflexão sobre as relações de troca estabelecidas nas trajetórias cotidianas de pessoas cegas a partir da necessidade de ajuda para circularem em cidades inacessíveis, com especial atenção para o cruzamento entre os marcadores sociais de gênero e deficiência. Sem perder de vista os conceitos de cuidado, dependência e autonomia que alimentam a discussão, proponho, inspirada em Mol (2008), um olhar para a forma como a dimensão localizada da ajuda é capaz de articular diferentes modos de agir e pensar a deficiência. Partindo do relato de pessoas cegas sobre suas experiências de serem ajudadas nas ruas, avalio as condições da relação de troca que se estabelece em encontros deste tipo. A reflexão toma como base a pesquisa realizada sobre a percepção de mundo de pessoas cegas durante meu doutoramento (von der Weid 2014). No material de campo encontram-se entrevistas com profissionais do Instituto Benjamin Constant (IBC) ${ }^{3}$, etnografia e observação participante realizada nos atendimentos da área de reabilitação do IBC, além de deslocamentos ${ }^{4}$ e entrevistas com pessoas cegas ${ }^{5}$.

Considerando a variabilidade da relação de ajuda no contexto estudado procuro pensar, de forma mais ampla, sobre a qualidade das relações sociais de troca entre pessoas deficientes e não-deficientes no espaço público. A reflexão coloca situações etnográficas em diálogo com a forma como a dimensão da ajuda tem sido vista pelo care studies e disability studies.

\section{Inacessibilidade urbana e o imperativo da ajuda nos deslocamentos}

Ainda que seja um 'bengalante' ${ }^{6}$ experiente, em seus trajetos pelas vias públicas de uma cidade como o Rio de Janeiro uma pessoa cega vive uma situação social bastante corriqueira: a de precisar pedir e re- 
ceber ajuda. Seja para atravessar uma rua, para descobrir o número do ônibus que está chegando no ponto, para pegar o metrô ou encontrar a portaria de um prédio, a ajuda humana é um canal de navegação crucial em seus itinerários. $\mathrm{O}$ depoimento de Renata é ilustrativo:

"Eu creio que a maior dificuldade (com a cegueira) para mim em particular, não sei se é a maior dificuldade para todos os cegos, mas eu creio que sim, é a locomoção. É realmente complicado porque primeiro que as ruas são muito esburacadas, é muito complicado de andar, é muito violento. Tem um monte de carros parados na calçada e isso complica para andar. Tem gente de rua dormindo no chão, morador de rua. Também complica. Eu vou para lugares conhecidos sozinha. Por exemplo, eu venho para cá (IBC) e vou para casa com tranquilidade, mas sei lá, me manda ir para um lugar que eu não conheço? Não sei se eu teria tanta coragem assim, sabe? A locomoção, para mim, acho que é a maior dificuldade" (Renata).

No dia a dia de uma cidade como o Rio de Janeiro, a ineficiência de transportes públicos, a infraestrutura precária de ruas e calçadas, a ausência de sinalizações sonoras, a desregulação, interrupção ou a falta de piso tátil nas ruas e prédios públicos e a desordem urbana são elementos que concorrem diariamente para a inacessibilidade e redução da mobilidade de pessoas com deficiência visual. Para ir e vir precisarão contar com outros seres, humanos ou não-humanos, que se tornam vetores de acesso aos lugares ou aos serviços.

Para mapear a mobilidade de pessoas cegas pela cidade, os empecilhos superados, as estratégias elaboradas e a crucialidade da relação de ajuda, propus a alguns pesquisados um dispositivo simples de investigação com o objetivo de registrar seus deslocamentos cotidianos pelo período de uma semana, incluindo informações sobre os locais frequentados, a finalidade do deslocamento, o meio de transporte utilizado e os momentos em que precisou contar com a ajuda de outras pessoas, conhecidas ou desconhecidas (von der Weid 2014). As ajudas para atravessar a rua ou parar o ônibus no ponto são do tipo cíclicas nos mapeamentos e imprescindíveis na rotina de qualquer pessoa cega que transita na cidade? 
A experiência da rua em sua materialidade e também as relações sociais que ali se desenvolvem terão impacto na liberdade de ir e vir de uma pessoa cega. A exclusão que acontece pelas barreiras materiais que dificultam sua livre circulação pela cidade é por vezes compensada pelas ajudas que recebem. A territorialidade flutuante de cegos está na mobilidade e nos olhos das pessoas anônimas que os auxiliam nas ruas, vetores de navegação no espaço urbano e fixação em territórios (Perlongher 2008). Tais vetores, no entanto, sofrem variação. A ajuda que se pede e a que se recebe não é plana, existem graus variados de necessidade, de acordo com o objetivo final, as características específicas de quem precisa de ajuda e de quem se oferece para ajudar, se o lugar é conhecido ou desconhecido, se o período é diurno ou noturno, se é um ambiente doméstico ou público ou, ainda, um meio de transporte. É possível também fazer uma tipologia das ajudas em função do grau de proximidade da pessoa que a oferece na rede afetiva e, consequentemente, o grau de familiaridade com a cegueira: parentes ou pessoas próximas; funcionários de empresas de transporte ou estabelecimentos comerciais, que podem ou não ter recebido treinamento para conduzir pessoas cegas (mercado, banco ou metrô, por exemplo); pessoas desconhecidas que encontram na rua.

Em uma cidade marcada pela inacessibilidade e por zonas de segregação sócio-espacial, as ajudas configuram uma rede de mobilidade de pessoas cegas que as permitem ir e vir no espaço urbano. Ao seguir a variação qualitativa das relações de ajuda, procuro pensar as possíveis contribuições da dimensão localizada desta relação no contexto urbano de uma cidade latino-americana para a discussão sobre as noções de cuidado, dependência e autonomia na deficiência em teorias forjadas em contexto anglo-saxão, em sociedades que tem ou tiveram estado de Bem-estar social.

\section{'Guia vidente' - a dimensão técnica da ajuda humana}

Se locomover com segurança e independência na cidade, o objetivo último do aprendizado das técnicas de Orientação e Mobilidade 
$(\mathrm{OM})$ na reabilitação, inclui saber pedir e contar com a ajuda de outras pessoas. $\mathrm{O}$ momento de pedir ajuda na rua é considerado pela Terapeuta Ocupacional (TO) que realiza o atendimento um dos mais críticos no aprendizado de OM. É saber comunicar a melhor forma de ser ajudado para quem oferece ajuda. Dizer, por exemplo, para a pessoa que está ajudando que ela deve avisar se precisarem atravessar uma passagem estreita, aí a pessoa cega já se posiciona por trás do guia. E é também não descuidar em momento algum da bengala, utilizando-a para resguardar o lado externo do corpo que fica desprotegido. É nos atendimentos de OM que a dimensão técnica da ajuda vai sendo incorporada no vocabulário e corporificada nas práticas das pessoas cegas.

Pedir ajuda na rua significa se deslocar em companhia de alguém. A TO comenta que sempre tem gente na rua que está disposta a ajudar, mas acrescenta que, ainda que o guia temporário tenha boa vontade, são poucas as pessoas que têm experiência com o modo de existência do deficiente visual para saber a melhor forma de ajuda-los. Existem formas mais ou menos eficientes para isso. Na técnica de 'guia vidente', a pessoa cega deve andar meio passo atrás do guia, posicionando a mão em seu antebraço, um pouco acima da altura do cotovelo, segurando com o polegar do lado externo e os outros dedos na parte interna do braço do guia, formando com o seu próprio braço um ângulo de cerca de $90^{\circ}$. A técnica permite a interpretação dos movimentos do guia por meio da percepção cinestésica.

As pessoas que oferecem ajuda, em geral, não conhecem as técnicas. Acontece de segurar a pessoa cega pelo braço, puxar pela mão ou então agarrar diretamente a bengala. É uma atitude que imediatamente desequilibra alguém que é cego. Quando sente alguma abertura numa eventual conversa no percurso, Camila procura ensinar algumas posições básicas que facilitam a locomoção partilhada:

"Quando você aprende OM você sabe que você é quem tem que segurar na pessoa que guia, né, e geralmente o guia quer segurar 
em você, na rua. Eles não sabem. Aí cabe a gente - 'olha, deixa eu segurar em você? Porque é melhor para mim, eu vou observando os seus movimentos'. Quer dizer, outra pessoa que ele for ajudar ele já sabe, né? E a outra pessoa às vezes pode ter uma inibição de falar, então eu explico -'olha, eu estou falando porque as outras pessoas às vezes...', - 'poxa, super legal você falar', - 'é, porque fica melhor para mim'. Aí eu explico, vou conversando como é que é”.

Camila fala de uma preocupação também comum a outros entrevistados, a responsabilidade de ensinar pessoas não deficientes a guiar pessoas cegas, informando as melhores posições corporais e os ajustes necessários para se exercer a função com alguma eficiência, a fim de que outras pessoas cegas que possam eventualmente precisar da ajuda desta pessoa se beneficiem do aprendizado. $\mathrm{O}$ metrô seria o sistema de transporte público que, na opinião dos pesquisados, estaria mais preparado na cidade do Rio para atender a uma pessoa cega. Ao invés de pedir ajuda a um desconhecido, que pode não querer ou não saber ajudar, os funcionários recebem treinamento para embarcar deficientes visuais, ou seja, aprendem a técnica. Para Dora faz diferença porque não é caridade ou favor, faz parte do serviço deles.

A necessidade de ajuda, entendida como assistência técnica, não é percebida como sinal de dependência daquele que precisa dela, mas sim como uma espécie de prótese que, tal como a bengala, promove a autonomia. A ajuda como suporte toma como base o modelo social da troca entre atores independentes, a provisão de cuidado seria uma questão meramente funcional, material ou instrumental (Kittay 2011). A independência seria cada vez maior quanto mais a pessoa com deficiência tiver controle sobre o tipo de assistência que precisa e a forma como será realizada. Entretanto, como lembra Mol (2008), e como também aparece no relato de Camila, o cuidado não se opõe à tecnologia. A assistência técnica não é previsível ou transparente e também deve ser realizada de forma cuidadosa. 


\section{Quando a ajuda despersonaliza}

Uma parte importante do estigma experimentado por pessoas com deficiência é ser tratado como se fosse criança, pessoas que tem que ser protegidas ou tuteladas, devem ser 'vistas mas não são escutadas', precisam que os outros tomem decisões por elas, não podem viver ou trabalhar de forma independente (Shakespeare 2000). Tais processos de infantilização, relacionados à situação de dependência, moldam experiências diárias de pessoas com algum grau de necessidade de ajuda e podem gerar sentimentos de marginalização social, humilhação ou vulnerabilidade. Casos extremos de invisibilidade aparecem em relatos que falam de despersonalização, como se a cegueira tivesse o efeito de transformar quem é cego em uma espécie de objeto que se muda de lugar. Nesta modalidade de ajuda, as pessoas só conseguem se relacionar com a cegueira através da projeção do estereótipo de incapacidade. Um relato comum é a experiência de chegar a um local - festa, reunião, consultório médico - e ser logo imobilizado em uma cadeira. Camila descreve:

"Em festa de vidente, comando é a palavra, o tempo todo no comando. O lugar, botam a gente... geralmente, infelizmente, botam em um lugar isolado. Isso aí todo mundo já conversou. Não digo festa de família muito íntima não, mas se você vai numa festa maior, eles vão te colocar num lugarzinho ali e ali te dão o salgadinho. É o que eu falo, não é maldade, é o jeito que eles sabem tratar. Não tratam igual. Então acha assim - vou botar a Camila sentada ali', aí me bota sentada ali, mas esquece, não é chatice não, mas pô... 'você quer sentar, Camila?', eu falaria - 'não' ou - 'quero, brigada' ou -'não, tá bom aqui em pé'. Como a pessoa é cega... geralmente as pessoas que não enxergam, você já observou? Até pelo próprio cuidado, você chega num lugar e já te botam num lugar sentado em uma cadeira”.

Camila conta a história com humor, mas sua recorrência revela, mais do que a inabilidade pontual de pessoas que enxergam de lidar com a diferença da cegueira, uma espécie de confinamento de corpos comparável ao que Bourdieu (2003) identifica nas práticas sociais de 
gênero. Aqui, o confinamento simbólico de pessoas cegas se expressa no acoplamento a um objeto, a cadeira, que em eventos sociais limita o movimento corporal, circunscrevendo seu corpo a um canto. Mas também ocorre quando não se dirige a palavra à pessoa cega, apenas ao seu acompanhante, submetendo o outro à inexistência pela atribuição da incapacidade de representação. Eu mesma vivenciei a situação incontáveis vezes quando em companhia de uma pessoa cega, especialmente em bares ou restaurantes. Renata exemplifica:

"Eu nem sei se conta, porque já aconteceu com todo mundo. Por exemplo, eu estou em pé e tem uma cadeira. Aí, ao invés da pessoa perguntar 'você não quer sentar? Senta aqui', ela pergunta pra minha mãe ou quem tiver do meu lado 'ela não quer sentar? Senta ela aqui'. Como se eu tivesse, sei lá, um problema de fala ou um problema mental, uma coisa assim. Isso incomoda. Isso te despersonali$z a$, faz como se você não tivesse vontade, como se você precisasse de um intérprete, de um mediador, de alguém que falasse por você. Está colocando o cego sem opinião né?" [grifo meu].

Nos casos mencionados é como se a ajuda retirasse o status moral da pessoa e a sua autonomia enquanto sujeito, tanto de escolha, quanto de movimento. A relação se dá apenas através do impedimento físico e da projeção de incapacidade, o que tem como efeito levar à imobilidade no acoplamento de corpos cegos a um objeto, novamente a cadeira. Ou ainda à objetificação por meio da manipulação dos corpos cegos à revelia da sua vontade: segurar pelo braço, puxar, empurrar, etc., são situações recorrentes no cotidiano da rua ${ }^{8}$. Quando a ajuda despersonaliza ela remete aos estereótipos de infantilização, tutela e caridade na relação com a deficiência.

Silvers (1995) acredita que a estrutura mesma das relações de cuidado, por pressupor a assimetria entre quem cuida e quem recebe, convida à marginalização de quem quer que ocupe a posição de dependente. A prática moral do cuidado requer o pretenso desamparo da parte de quem o recebe - sejam idosos, crianças, doentes ou deficientes. No caso da deficiência isso implica na suposição prévia de dependência e, invariavelmente, pode resultar em imobilização. Em 
um sistema em que o cuidado é a forma primária com que não-deficientes se relacionam com pessoas com deficiência, a autora acredita que os últimos se tornam socialmente incumbidos de professar a incompetência, ou ao menos é assim que são vistos socialmente, mesmo quando são mais competentes que os primeiros ou mesmo quando estão em pleno domínio de uma situação.

Boa parte das situações que despersonalizam numa interação passa por um mecanismo de atribuição de representações. Dora fala sobre um tipo social 'normal' que encontra nas ruas, aquele que só se relaciona com os estereótipos:

"Tem aquelas pessoas que elas jamais conseguem sair do estereótipo. Elas só conseguem se relacionar comigo falando da cegueira, se relacionando através da cegueira. Aquilo é uma coisa para elas tão espetaculosa que não conseguem perder o foco daquilo em momento nenhum. [...] Uma pergunta clássica: 'você é assim de nascença?'. Perguntam exatamente com essas palavras: 'você é assim de nascença?'

O: E o que você responde?

Aí depende. Eu já respondi de tudo, já experimentei todas as respostas, porque eu não tenho nenhum compromisso com a verdade, né? A pessoa pergunta o que ela quer, eu respondo o que eu quero, tá certo? Eu já respondi que sim, já respondi que não... As pessoas perguntam por que da sua resposta elas vão atribuir a você a projeção que elas têm na cabeça delas lá sobre o que é uma pessoa que ficou cega depois e o que é uma pessoa que nasceu cega. Elas querem saber isso para saber qual é o lixinho que ela vai despejar em cima de você. Eu defino assim, é um mecanismo de projeção, é você não querer ver aquilo em você, projeta no outro. Querem saber se a pessoa nasceu cega ou se ficou cega depois para saber qual a lata de lixo, se é lixo orgânico, qual é o lixo que ela vai depositar em cima de você. Sou bem contundente, né? Mas para mim é isso. O: Mas o que vem depois? Você diz 'nasci cega'...

'Ah, então já está acostumada' ou 'então é melhor assim'... Então nada, cara, qual é? Sabe lá? Eu nasci assim e foi uma merda, entendeu? Porque eu passei a infância como pessoa cega, quem é que diz que é melhor assim? Claro que não é. Isso é problema dele - ver e depois perder - não é o meu. O quê eu percebo? Se você diz que nasceu assim, por um lado a pessoa fica mais sossegada, porque ela 
não está se deparando com o trauma da perda. Se você diz que perdeu a visão depois, ela fica mais aflita porque isso pode acontecer com ela, mas ao mesmo tempo ela também se relaciona como se você fosse uma pessoa igual a ela, porque você já viu. Porque o cara que nunca viu, por um lado é mais tranquilizador, mas por outro lado ele é outro bicho lá, de outra espécie, porque ele nunca viu, sabe como é, nunca viu a luz do dia, é outra coisa, é outro mundo, vive em outro mundo, aquele negócio. Então é lixo de qualquer jeito, cara, você não escapa não. Tô fora. Por isso que eu te falo, eu respondo qualquer coisa. Porque aí também me propicia fazer essas experiências, aí sou eu que estou fazendo as minhas experiências".

Como já apontou Oliver (1990), as pessoas com deficiência precisam confrontar diariamente representações culturais sobre a sua condição em que as ideias de incapacidade, tragédia e infortúnio se agregam, fazendo da 'narrativa da tragédia pessoal' uma espécie de profecia social que acaba gerando as condições da sua confirmação. Para Martins (2006), as representações sobre a cegueira adquirem um caráter duplo, advém tanto do histórico social e cultural quanto de mecanismos de projeção individual imaginativa, que o autor chama de 'angústia da transgressão corporal', informados no corpo de quem enxerga, na diferença corporal que resiste à desconstrução. Ainda que o visuocentrismo em que vivemos tenha um viés sócio -histórico, a visão tende a ser um sentido crucial para quem dela faz uso. Consequentemente, a projeção imaginária da cegueira por um corpo que vive visualmente acaba forjando ideais de prisão sensorial e incapacidade.

Pela experiência de Dora, as pessoas se relacionam é com as suas próprias cegueiras, com aquilo que a cegueira significa para elas. Cegueiras projetadas que em nada se parecem com a experiência fenomenológica e existencial de quem é cego. Tal uso que se faz do corpo por quem vê é supostamente empático, aparece como uma tentativa de aproximação do 'sofrimento' do outro. Sofrimento também já projetado, uma vez que o cego que se encontra andando sozinho na rua muito possivelmente já passou da fase do 'luto' ou pode ser um cego congênito e nunca ter vivido a experiência da perda. A projeção acaba 
tendo o efeito inverso e perverso de um afastamento ainda maior, pela angústia que gera, estruturalmente situada na visão.

Pessoas não deficientes constantemente afirmam que não conseguem se imaginar desejando viver se tivessem que ser confinadas a uma cadeira de rodas ou se perdessem a visão. Silvers (1995) identifica que haveria uma espécie de compulsão nas sociedades ocidentais para descartar os deficientes como anormais, alguém que ocupa um estado físico - ontológico - impensável para o outro. A afirmação sugere que, para pessoas não deficientes, ser deficiente significa viver uma vida inferior. O forte estereótipo tem, para a autora, uma dupla implicação ética. A primeira é que demonstra que a diferença da deficiência não é do tipo que possa ser descartada como um atributo externo e contingente e, portanto, acidental para o ser moral de uma pessoa. A outra é que os apelos ao critério moral básico para a convivência entre diferentes - fazer ao outro o que gostaria que fosse feito consigo caso estivesse na posição do outro - se mostra ineficiente quando se tratam de pessoas com deficiência. Pois, se os indivíduos considerados 'normais' não conseguem avaliar como seria se estivessem no lugar de uma pessoa 'danificada', então as afirmações sobre como gostariam de ser tratados caso fossem deficientes são opacas para eles.

A aversão à própria ideia de ser ou se tornar deficiente afasta nossa compreensão da deficiência de seu próprio ponto de vista. Ao invés de estender a moralidade para alcançar mesmo os indivíduos com deficiência, a tentativa de se imaginar no lugar do outro serve para, num primeiro momento, amplificar o impacto de seus impedimentos, a ponto de excluir estes indivíduos do reconhecimento moral normal. O significado que o impedimento ou a lesão tem para pessoas não deficientes é uma barreira concreta para o reconhecimento da diferença de pessoas com deficiência. A forma como outras pessoas reagem às suas diferenças, considerando sua condição inimaginável ou suas vidas como descartáveis, pode significar que a resposta de pessoas com deficiência seja negar sua diferença, como se disse do primeiro modelo social de deficiência (Kittay 1999). 
Longe de ser uma relação que ocorre em locais específicos ou com pessoas desconhecidas, a família ${ }^{9}$ também pode ser um dos agentes centrais que contribui para reproduzir uma espécie de dominação que se corporifica (Bourdieu 2003). No IBC ouvi o seguinte depoimento de uma das TOs que faz o atendimento de Atividades da Vida Diária $(A V D)^{10}$ :

"Tem aqueles familiares que, por medo deles se machucarem, por medo de outras pessoas se machucarem e acabar quebrando tudo dentro de casa, entre aspas, fala assim - 'fica aí que eu pego para você', - 'fica aí que eu faço isso para você, faço aquilo para você', e aí acaba que o deficiente visual fica uma estátua dentro de casa. Eu tinha uma aluna que ela entrava aqui na AVD, se posicionava na parede de entrada, literalmente, ela ficava de costas para a parede, com as costas encostadas na parede, igualzinho uma estátua. Uma agonia mesmo. Eu falava - 'fulana, vambora, vamos se movimentar, vamos fazer isso, aquilo outro, quando você entrar você coloca a sua bolsa lá, vai lavar a sua mão e a gente vai fazer atividade'. Se eu não desse o comando verbal para ela fazer qualquer coisa ela ficava no cantinho da parede, com a bengala aberta na frente do corpo, parada. Sem falar, sem se mexer, sem fazer absolutamente nada. E esse era o retrato da vida dela todos os dias dentro de casa. Até pelo medo, pelo receio de provocar uma reação no familiar. Porque muitas vezes, como tem pessoas compreensivas, tem pessoas agressivas na família - 'você fez isso! você fez aquilo outro!', - 'você só sabe fazer coisa errada! Só sabe quebrar tudo!”.

Nos atendimentos da (re)habilitação, o estímulo ao movimento, à descoberta e exploração do ambiente, passam por um processo de destencionamento de um corpo que pode ter sido paralisado pelo medo que, em casos como o descrito, foi corporificado em nome do cuidado. Liberdade e autonomia que se conquista pelo movimento, pela exploração corporal dos espaços, pela prática de encontrar formas de fazer as coisas por si, do seu próprio jeito. O cuidado pode tanto promover a abertura e o acesso quanto ser paralisante, quando destitui o outro da sua capacidade de agência.

Afirmar a interdependência humana não exclui da discussão o fato de que nem todos somos dependentes da mesma maneira, ou 
seja, não apaga as relações de poder e dominação às quais, histórica e concretamente, estão submetidas boa parte das pessoas deficientes, ainda que em graus variáveis. E, como aparece no depoimento da TO e é também sublinhado por Morris (2001) e Shakespeare (2000), a própria família também pode ser o locus da opressão de pessoas com deficiência, o que pode se dar pelo paternalismo ou superproteção. Para Morris (2001), o foco naquele que cuida pode ter o efeito de silenciamento ou objetificação de quem tem necessidades específicas de ajuda ou, ainda, colocar em segundo plano as relações públicas e privadas de poder e subordinação que pessoas com deficiência estão cotidianamente sujeitas.

\section{Gênero e deficiência visual na arena da rua}

As interações sociais que ocorrem no espaço público da rua fornecem materiais que possibilitam entender melhor as categorias e posições sociais que entram em relação nessas situações. Os momentos de imposição da ajuda explicitam a vulnerabilidade que mulheres com deficiência visual estão expostas em seu cotidiano. Beatriz relata uma vivência de imposição de ajuda que analiso pela perspectiva da 'situação social', conforme Goffman (1966). Nossa arena é o espaço público da rua, um determinado percurso no centro da cidade do Rio de Janeiro.

Beatriz saía de uma imobiliária localizada no início da Av. Rio Branco, perto da Praça Mauá, no centro do Rio de Janeiro. De lá precisava ir até uma loja na Rua da Alfândega. Começa a andar pela calçada. Sem avisar, e sem perguntar se ela precisava de ajuda, um sujeito se aproxima, dá as mãos a ela entrelaçando os dedos e segurando firme e começa a andar com os braços colados, segundo ela, como se fossem namorados. Depois de alguns passos pergunta para onde ela vai. Apreensiva, ela responde que está indo para um pouco depois da Presidente Vargas. Atravessam a primeira rua. Quando chegam na faixa de pedestre, o sinal estava aberto para os carros. Os dois param 
e ela se volta para o homem e diz: "amigo, já está legal já, não precisa ir não, daqui dá pra eu ir tranquilo”. Ele responde, em tom enfático: "fica quietinha aí que eu já falei que eu vou te levar". Beatriz na hora pensou "F... e agora?". Continuou andando e pensando como faria para se livrar do sujeito. Atravessaram as quatro pistas da Presidente Vargas e já estavam andando pela Rio Branco. Ele desce o meio fio e faz menção de atravessar com ela. Naquele momento ela estanca firme e fala alto: "eu não vou atravessar". Tenta desvencilhar sua mão. Ele não diz nada, mas cola de novo lado a lado, segurando forte em sua mão. Quando chegam em frente à Alfândega ela para novamente e uma terceira pessoa se aproxima, um homem, que pergunta "a senhora quer alguma coisa?". Ela aproveita que alguém se dirigiu a ela e se despede novamente do primeiro sujeito: "amigo, muito obrigada, valeu mesmo, aqui está bom”. Ele finalmente larga a mão dela, que então se despede rapidamente dos dois homens e segue adiante. Logo à frente o segundo sujeito a aborda novamente, se apresenta, diz que é policial e conta que tinha sido uma quarta pessoa, um senhor, que viu a cena de longe, estranhou e o avisou. Falou que o primeiro sujeito era um cara 'esquisito' e que ainda estava na rua. $\mathrm{O}$ policial aguarda ela resolver o que precisava fazer na loja e depois a conduz até o metrô.

A abordagem do sujeito a Beatriz de saída já infringe as regras de conduta ou as convenções sociais de cortesia. Ela dá sinais de desconforto. Primeiro, de maneira educada, utilizando expressões verbais que indicam querer finalizar a interação. Em seguida, de forma mais direta quando tenta puxar a mão ou quando se recusa a atravessar, falando em tom de voz alto. Seus sinais são percebidos por alguém de fora que compreende a situação e aciona um terceiro elemento, um policial que, além de também ser homem, é capaz de interferir por estar em uma posição social de autoridade.

Quando considera a vulnerabilidade social nos espaços públicos, Goffman (1977) atenta especialmente para as diferenças de gênero, concluindo que as mulheres estão, de uma maneira crônica, muito mais vulneráveis a sofrerem avanços impróprios. No caso que 
descrevemos, a vulnerabilidade a riscos como violência física ou assedio sexual se torna dupla, tanto pela questão de gênero quanto pela deficiência visual, que traz consigo o imperativo da ajuda. Por ser tão necessária no cotidiano da pessoa cega a ajuda também expõe a uma espécie de abertura, mesmo que involuntária, para a possibilidade de, a qualquer momento, ser abordada sob a máscara do auxílio, seja a real intenção da abordagem, seja um disfarce.

Embora possa ajudar o reconhecimento de que, enquanto seres sociais, somos todos vulneráveis e dependentes uns dos outros, Morris (2005) considera que depender da assistência de outras pessoas para realizar tarefas íntimas, por exemplo, não é o mesmo que depender de um mecânico para consertar o seu carro. Depender de alguém para atravessar a rua não é o mesmo que depender do funcionamento do transporte público para chegar ao outro lado da cidade. Mesmo que a dependência seja reconhecida como uma parte essencial da condição humana, isso não deve esconder o fato de que a experiência prática de algumas pessoas sobre seus corpos as colocam em um risco muito maior de perder seus direitos do que a maior parte da população. Para Butler (2015), existem determinados enquadramentos normativos atuando na produção de corporificações na vida social que diferenciam as vidas, levando a uma alocação diferencial da condição precária. $\mathrm{O}$ reconhecimento da vulnerabilidade enquanto condição humana essencial parece um passo importante na crítica ao sujeito moderno, mas podemos levar a crítica mais longe ao problematizar os enquadramentos que tornam possíveis que determinados corpos sejam entendidos como mais precários que outros, as normas que operam para tornar certos sujeitos pessoas 'reconhecíveis', 'normais', enquanto outros se tornam mais difíceis de reconhecer. Esta parece uma questão fundamental para se pensar as relações sociais de deficiência no espaço público. $O$ caso relatado por Beatriz é ilustrativo do entrelaçamento de duas diferenças, gênero e deficiência, que aumenta a condição de precariedade e vulnerabilidade. Mulheres cegas, justamente pelo imperativo da ajuda produzido por cidades inacessíveis, 
acabam ficando mais expostas nas ruas ao risco da violência, assédio e abordagens indesejadas.

A ajuda, portanto, não é apenas um elemento que promove a ampliação e o domínio de territórios na cidade, também pode ser um elemento que restringe ou que interfere na circulação. Não só quando não é bem vinda, como no caso de Beatriz, mas também nas ocasiões em que acaba levando para territórios indesejados, ou ainda quando é escassa ou inexistente. A indispensabilidade da ajuda em cidades despreparadas para a diversidade corporal de seus habitantes faz com que a circulação de pessoas que necessitam dela sofra variações em função dos turnos. À noite a mobilidade de pessoas cegas fica mais restrita, em função da queda tanto na oferta quanto na qualidade da ajuda. Caetano fala sobre a mudança no estado afetivo de quem circula no período noturno:

"À noite já começa a ficar complicado (encontrar ajuda) porque tem menos gente na rua, as pessoas estão mais apressadas, sei lá. As pessoas andam com medo também... Por exemplo, passa uma mulher sozinha, às vezes você está parado num lugar, ela não vai parar, principalmente se não tiver assim bem claro que você é deficiente visual, as pessoas podem aplicar golpe por aí. As pessoas desconfiam de tudo e de todos, né? À noite é sempre mais perigoso, as pessoas têm medo de se expor, de correr risco. Então já anda com pressa, já andam correndo".

A decisão de evitar sair à noite não é somente uma questão de prudência pela insegurança urbana, motivo para menor circulação de qualquer pessoa mais preocupada em se precaver numa cidade violenta como o Rio de Janeiro, mas, no caso de pessoas cegas, também está vinculada à diminuição da possibilidade de navegação devido à menor oferta de ajuda. A mudança da atmosfera das ruas em horários noturnos - aumento do risco e da insegurança - faz com que as pessoas também mudem sua tonalidade afetiva ao circularem por elas - andem mais depressa, desconfiadas -, o que diminui as chances de ser ajudado. Se uma pessoa cega não tem a possibilidade financeira de se deslocar em transporte privado, seu ir e vir se restringe ao trem ou 
metrô, formas mais certas de deslocamento, mas com horários e destinos restritos, ou ao ônibus urbano. Dependendo da linha, o ônibus até pode circular a noite inteira, mas para uma pessoa cega utilizar tal transporte precisa contar com a vetorização humana, que costuma rarear em certas condições. Nas palavras de Beatriz:

"Eu evito sair de casa dia de domingo porque... bicho, quase não tem pessoa na rua. Aí chega no ponto de ônibus não tem ninguém. Você fica ali parada no ponto de ônibus um tempão, os ônibus só passando, passando, passando... dá vontade de sair fazendo sinal para todos, né? O que te interessar você entra. Mas nem assim rola, porque você pode fazer sinal e ele parar lá na frente, o cara vai... é impressionante. Você está sempre realmente dependendo do outro, não tem jeito".

Ruas vazias e sem movimento, dias em que o comércio está fechado e locais ermos ou escuros como pontes, viadutos, becos e vielas são espaços que impõem a sensação de insegurança aos corpos femininos, que adotam diferentes estratégias para evitar passar por estes locais - mudar o percurso, acionar familiares ou amigos, recorrer ao transporte complementar como táxi, van ou mototáxi. Os pontos de ônibus são locais particularmente ameaçadores para a integridade física das mulheres. As relações de dominação e as desigualdades sociais implicam em privações do direito à mobilidade dos corpos nos espaços urbanos (Pires 2016). As mulheres com deficiência encontram dificuldades ainda maiores para exercer seu direito à cidade (Lefebvre 1969) e acessar oportunidades que o espaço urbano tem a oferecer. $\bigcirc$ atravessamento de gênero e deficiência coloca tais mulheres em situação de dupla vulnerabilidade e mais suscetíveis a experimentar a violação de direitos, tanto nos espaço urbanos quanto em serviços públicos (Nicolau, Schraiber \& Ayres 2013).

Um dos aspectos que caracterizam a relação de interação na situação de ajuda, que Goffman (1975) associa à visibilidade do estigma, é o das pessoas se sentirem livres para iniciar conversas, fazer perguntas e tecer comentários em torno da situação do indivíduo estigmatizado. 
Infere-se que a pessoa que precisa de ajuda pode ser abordada à vontade por estranhos, desde que pareçam simpáticos à sua situação. $\mathrm{O}$ elemento tem também o duplo atravessamento de gênero e deficiência. Mulheres cegas, como vimos, podem ser abordadas não apenas verbalmente como fisicamente, tendo o seu espaço de proximidade corporal invadido contra a sua vontade. As abordagens verbais também podem conter traços de julgamentos morais. Ana conta que uma das opiniões que recebe sem pedir, é que ela, por ser deficiente e mulher, não deveria andar sozinha na rua. A justificativa é que seria 'perigoso':

"Eu estava vindo de São Gonçalo, eu trabalhei lá em câmara escura, então estava cansada, com o corpo grudento, cheiro de química na cara toda, no cabelo, em tudo. Veio o moço e falou assim 'a senhora está indo pra onde?', eu falei 'vou pegar o 107', 'a senhora aceita ajuda?', 'aceito sim senhor'. Aí ele falou 'a senhora devia arrumar uma pessoa pra andar com a senhora, a senhora não pode andar sozinha, não', eu falei 'por quê?', 'ah, porque a senhora é cega, não pode andar sozinha, é perigoso, como é que cego vai saber... por exemplo, agora a senhora precisou de alguém para levar a senhora para o ônibus'. Aí eu tava meio... falei assim 'ô moço, vem cá, deixa eu te fazer uma pergunta...'. [risos] Que vergonha, ai meu Deus... não é de você, é de eu ter falado isso pra ele. 'Se você não enxergasse...'. É a maneira mais suave de dizer que é cego [risos]. 'Se você não enxergasse e tivesse uma namorada e quisesse sair com essa namorada e tivesse um acompanhante, você ia gostar que o acompanhante visse vocês se beijando? Ia gostar?'. Aí ele 'É, isso é'. Atravessou comigo as pistas, não disse mais nada, me colocou no 107. Eu dei uma sorte, por que ele era homem, podia ter me sacaneado, eu não tinha que ter falado isso, não... Eu não sou santa, tá? Aí é o meu lado que...

A conversa que Ana estabelece com o homem na relação de ajuda não se constrói como diálogo ou troca, mas em torno do que se diz em nome e sobre o lugar do outro. E o que se diz está relacionado às narrativas culturais que veem a deficiência como incapacidade e a mulher cega como alguém que precisa estar sempre acompanhada, englobada pela família. Ser mulher deficiente é viver sob constante ameaça de risco ou perigo iminente - de cair, de falhar, de passar vergonha 
por não conseguir cumprir as regras tácitas de comportamento que governam a vida social ordinária ou de não conseguir manter o comportamento considerado apropriado para determinada situação (Keith 1996) - seja este risco real ou projetado. No caso trazido por Ana, a aura de diminuição e incapacidade que engloba a deficiência se soma aos estereótipos culturais de gênero. A constante vigilância da criança com deficiência em nome do cuidado com a sua integridade física se prolonga na vida adulta, se tornando ainda mais proeminente no caso de mulheres deficientes que, na lógica tradicional e paternalista brasileira, são vistas como responsabilidade da família ou do marido.

Para Scully (2010), a administração da apresentação de si que as pessoas com deficiência precisam fazer nas interações sociais é uma forma de trabalho, que necessariamente precisa ser escondido para que a interação transcorra da forma desejada. Além de ter que lidar com um mundo físico que, historicamente, foi desenhado para excluir certas corporalidades, nas relações de ajuda é preciso também lidar com as projeções e preconceitos de pessoas não deficientes a respeito de um impedimento ou lesão e, nos casos mencionados, a respeito também dos papéis de gênero. Esse 'lidar com' implica controlar a apresentação de si, identificar o que a outra pessoa precisa saber ou quer sentir, avaliar quais estratégias são necessárias para se alcançar a ajuda que se precisa ou para se livrar dela, o que tem um custo significativamente alto de energia física e psíquica. Beatriz comenta sobre este desgaste:

"Você passa por trocentas situações 7 dias por semana, 30 dias por mês, 365 dias por ano. Todo dia você está submetido a trocentas situações, porque para mim, que saio de manhã e só volto de noite, eu passo por trocentas situações todos os dias. Fica muito cansativo. Você não consegue lidar mais com a coisa da mesma maneira. Nem todo dia você está com o mesmo humor, tem dia que você está de TPM, outro dia que você não está tão a fim de interagir, outro dia que você não está tão simpática... enfim, gente. Sabe? E a gente 'tem que...', eu não tenho que nada. É muito complicado. Às vezes eu me cobro 'coitada da pessoa, eu sei que ela não fez por mal'. Para não ser injusta estou optando por me calar. Não falo 
mais. A pessoa começa a falar um monte de coisa, eu fico quieta. É cansativo demais.

As estratégias desenvolvidas para manipular o encontro envolvem gerenciar elementos cognitivos e emocionais da interação, regular a informação e a percepção de modo que pessoas não deficientes possam processa-las para formar algum tipo de consideração pela outra pessoa e, paralelamente, gerenciar elementos afetivos, por meio da expressão das emoções estereotípicas apropriadas, ainda que o sentimento interno seja de cansaço, raiva, frustração ou medo. Um dos exemplos de emoções estereotípicas trazido por Scully (2010) é o da gratidão que se espera que as pessoas com deficiência expressem por terem recebido ajuda, mesmo quando, legalmente, teriam o direito de recebe-la. Eventualmente, pode ser necessário se conformar ao estereótipo, pois pode ser a única base na qual o contato pode se desenvolver e a interação atingir seu objetivo - ser ajudada de forma minimamente satisfatória. No caso das mulheres deficientes o trabalho é duplo. Na moral brasileira que regula o espaço público, extremamente marcada pela lógica tradicional e patriarcal, a mulher deficiente que anda sozinha na rua é percebida como alguém que não tem família ou que foi abandonada pela família, o que implica que os sentimentos de pena, caridade ou reprovação serão emoções estereotípicas comuns a serem gerenciadas pela mulher cega na relação de ajuda no espaço público.

$\mathrm{Na}$ interseção entre gênero e deficiência na mobilidade urbana há uma sobreposição de espaços de constrangimento, como a dificuldade para frequentar certas ruas em determinados horários ou locais, com os espaços de confinamento já que, devido à maior incidência da pobreza em famílias com pessoas com deficiência (França 2014), é provável que residam em zonas de segregação urbana involuntária. Estes são elementos que agravam a condição social de vulnerabilidade das mulheres com deficiência, podendo resultar tanto em diferenças de acesso físico a determinados espaços quanto em barreiras invisíveis 
criadas pelo olhar e controle social do outro, exercido em um contexto estruturado pela lógica da dominação masculina (Silva 2007).

\section{Afetividade e autonomia}

A ligação de um território com o seguinte no espaço público da rua não está definida e pode ser feita de uma infinidade de maneiras. Camila descreve uma das primeiras vezes em que, depois que perdeu completamente a visão, decidiu se aventurar sozinha até um local desconhecido. De seu depoimento emergem os vetores de navegação que atravessaram seu caminho e uma espécie de sinergia entre seu desejo, seu estado de espírito e a qualidade da ajuda que encontra no percurso.

"Tinha um aniversário em Campo Grande. Aí eu 'não vou não.. ah, não vou sabe?'. Mas aí eu estava em casa e 'ah, eu vou'. Liguei para a menina, 'como é que eu faço para chegar aí?', aí ela 'tu vem mesmo?', ficou toda feliz. 'Eu vou', 'tu vem nada...', 'vou sim, como é que eu faço para chegar aí de Madureira?', falei logo onde eu morava. 'Você pega tal ônibus, aí salta em Campo Grande, pega a Kombi Salim'. Aí fui me arrumar. Sabe quando você respira fundo? 'Eu vou'. Fui para o ponto. Cheguei no ponto e 'por favor, alguém pode ver o onibus tal para mim?'. Antigamente eu tinha horror assim de... achava que eu estava ocupando alguém. Aí eu peguei o ônibus. Quando você está bem, você se determina, as coisas vão se encadeando direitinho. Entrei no ônibus, o motorista era maravilhoso e o trocador também. Aí o trocador - 'passa, senta perto de mim, você vai para onde?', e eu 'Campo Grande', 'Campo Grande? Vamos fazer uma viagem longa'. Sentei. Estou indo, 1 hora, estou indo, 1 hora e meia, pensei 'gente eu to indo para onde?'. Aí ele virava e dizia assim para mim 'ó, ainda não chegou não tá? Já, já você vai estar chegando lá. Pra onde você vai?'. Peguei o papel, dei na mão dele, aí ele 'ah, você vai saltar no Salim'. A menina tinha me dado um mapinha. Quando chegou ele 'ó, tá chegando... chegou hein'. E eu 'tá bom, muito obrigada'. Aí ele 'peraí um instantinho, fulano cê vai ali pro Salim? Vai pegar a Kombi?', 'vou', 'acompanha ela pra mim?'. [O fulano] me acompanhou até a kombi. Eu fui. Quando chegou na Kombi 'moço, você conhece uma menina...'. Ela [a amiga] falou assim 'conversa com ele que ele vai me conhecer, eu pego sempre'. 'Conheço... pode deixar, eu te 
levo lá'. Gente as coisas foram assim, encadeando direitinho. Isso vai te dando mais força, sabe? Quando as coisas... mas aí eu botei uma coisa na minha cabeça. É que tem dia... nem sempre as coisas fluem assim. E nesse dia que as coisas não fluem você tem que ter muita paciência. Aqui o pessoal usa muito [a expressão] assim 'matar um leão por dia', que é a força que você tem que ter de levantar e sair. De estar sempre assim pedindo [internamente] tomara que tenha alguém legal por perto, que possa te ajudar. E se não for legal também que pelo menos 'quer atravessar?, aí atravessa e pronto, entendeu? E assim a tua vida vai”.

A situação rememorada por Camila traz novos elementos para entender a distribuição das ajudas no espaço aberto da cidade e as suas conexões com um estado mais intensivo que atravessa seu itinerário, podendo facilitar ou dificultar caminhos. Cruzar a cidade e ir a um aniversário em um bairro distante é parte de um movimento de desterritorialização e construção de um novo território para Camila. Para chegar lá ela precisa contar com esses vetores de deslocamento, força ou linhas de fuga que atravessam seu percurso (Deleuze \& Guattari 1997). Como o vetor de navegação não é um GPS, mas seres humanos, afetos emergem da interação. Ir a um lugar novo é uma decisão que demanda preparação anterior e determinado estado de espírito - desejar bons encontros que guiem o caminho e contar com a sorte. Como sugerem Guattari \& Rolnik (1996), o desejo produz, é criativo, agencia elementos e cria territórios. $\mathrm{O}$ novo território, ao mesmo tempo em que exige, materialmente, a descoberta de caminhos nunca antes percorridos, também se torna, por correspondência, a criação de um território afetivo interno de confiança e autonomia. Autonomia aqui não significa independência, mas uma disposição singular de enfrentamento do desconhecido, superando suas próprias barreiras de imobilidade ou dependência. Conquistar o novo encontrando os seus próprios meios para chegar lá.

Winance (2016) sugere uma ponte entre as noções de cuidado e deficiência por meio da reconstrução da noção de autonomia, não tanto pela ideia de autonomia relacional ou interdependência propos- 
ta pelos estudos feministas do cuidado, mas relacionando-a ao conceito de recalcitrância, inspirada em Stengers e Latour. A autonomia enquanto recalcitrância seria a capacidade de resistir de um sujeito, de mostrar descontentamento ou de discordar. Mesmo bebês possuem essa capacidade quando, ao demonstrarem seu desconforto por meio de choro, gestos ou recusa em fazer algo, influenciam a forma como são cuidados por seus pais. A autora propõe a ideia de 'autonomia crua' para falar da recalcitrância que emerge em todas as relações, que seria a marca mesma do sujeito, da pessoa que resiste ao que lhe é oferecido ou imposto.

Podemos ampliar a sugestão da autora a partir da experiência de Camila pensando a autonomia não apenas nos casos em que um organismo expressa resistência ao que lhe é oferecido, mas também, de forma positiva, pelo que é capaz de criar a partir do histórico das interações entre a sua corporificação particular e determinados ambientes. A autonomia de Camila emerge em atos concretos, como o seu deslocamento à casa da amiga. Um ato pragmático que é, ao mesmo tempo, autopoeiético, criador e cognitivo (Maturana \& Varela 1980): cria tanto as suas possibilidades de ir e vir na sua nova existência como pessoa cega, quanto um mundo que passa a ser conhecido e vivido dessa forma. À medida em que se atualiza, em novas idas e vindas, é algo que se torna parte de seu modo de vida, uma forma de subjetividade e um território de poder/fazer onde se desenvolvem suas capacidades de ser na cegueira.

Camila conta outro episódio que se passou na rua que, para ela, foi um sinal de que estava se recuperando do impacto que a perda da visão teve em se modo de deslocamento e na percepção de si:

"Ali eu notei que eu tinha me recuperado mesmo, me reabilitado. Porque eu tinha horror de me chamarem de ceguinha, eu me chocava, me magoava. E eu estava lá em Madureira, vindo na calçada com a minha bengala e aí um camelô lá do outro lado gritou -'ceguinhaaaaa'. Aí eu parei na hora. Eu estanco na hora. Aí eu fiquei parada, vendo o quê que ele queria falar para mim - 'ó, na sua frente tem obra'. E eu - 'é? E aí, como é que eu faço?', - 'quebra 
pra direita, agora vai, segue, isso...', aí me direcionou. E eu - 'muito obrigada, tá? Valeu', ele 'que nada...'. Aí eu pensei: gente se ele tivesse me chamado de ceguinha há um ano atrás, eu ia cair assim em prantos na rua. Naquele dia eu falei estou bem legal mesmo, tô passando no teste".

A forma como Camila reagiu à situação é representativa da conquista de um novo território, subjetivo e movente, como pessoa cega. Por meio de uma série de transformações corporais, educação da atenção e desenvolvimento de habilidades na reabilitação não apenas emerge uma corporalidade cega, com suas próprias limitações e capacidades, mas uma pessoa cega também vai emergindo, que é tanto produto quanto produtora de sentidos e de novas experiências sociais. A cegueira pode ser assim percebida como um conjunto de atitudes, de modos de ser e de fazer, de afecções ou habitus que são pouco a pouco corporificados para que uma nova forma de ser pessoa comece a ser descoberta. Como nas sociedades ameríndias (Seeger, DaMatta \& Viveiros de Castro 1979) aqui também é o corpo, ou uma certa corporalidade, que é capaz de articular sentidos e significados que corroboram para a construção da pessoa cega.

Hoje em dia, Camila vai para todo o lado sozinha e para isso conta muito com a ajuda de outras pessoas, por vezes anônimas, que direcionam o seu caminhar, moldam os desvios e as mudanças de direção em sua trajetória. A necessidade de ajuda, a interdependência (Kittay 2011), é um meio, um pressuposto relacional que tanto pode expandir - "quando as coisas se encadeiam direitinho isso te dá mais força" - quanto diminuir sua mobilidade e capacidade de agir - nem sempre as coisas fluem, pois ainda é preciso 'matar um leão por dia' para que pessoas cegas consigam transitar na cidade.

\section{Considerações finais}

As relações de cuidado e ajuda nas interações entre deficiência e não deficiência são tanto antídoto quanto veneno: podem ampliar a capacidade de agência dos sujeitos por meio do reconhecimento 
da interdependência como também podem servir para perpetuar a lógica perversa de dominação e exclusão que, na cegueira, se constrói pela imobilização dos corpos. Em português, a própria palavra cuidado, dependendo do uso em que é empregada, carrega a ambiguidade entre dependência e autonomia uma vez que remete tanto à ideia de ser atencioso com o outro quanto à dimensão do risco, quando soa, por exemplo, como um alerta: cuidado para não cair! Cuidado com a bola! Cuidado com o degrau! Cuidado com o buraco! Cuidado para não se machucar! E, no caso feminino, cuidado com os homens na rua! Cuidado com a violência!

Na sociedade brasileira, Da Matta (1985) observa que o mundo da casa (espaço privado) e o mundo da rua (espaço público) são mais do que meros espaços geográficos, sendo carregados de sentido, marcados por uma relação de oposição e de tensão, ao mesmo tempo em que interagem e se complementam. $\mathrm{O}$ autor caracteriza nosso sistema social por um valor fundamental, o da relação. Nos deslocamentos de pessoas cegas pela cidade do Rio de Janeiro encontramos redes de ajuda, sistemas de troca, pontos de encontro, instituições, arranjos, vetores, trajetos e muitas outras mediações por meio das quais a entidade abstrata do indivíduo com deficiência visual conseguirá efetivamente ter acesso e participar do cotidiano da cidade (Magnani 2002).

O cenário brasileiro enfatiza a dimensão ambígua das relações de ajuda no espaço público, que não pode ser desconectada de uma discussão a respeito do papel do Estado, dos equipamentos urbanos e das lógicas sociais que atravessam os lugares. Nesse sentido, a ajuda pode se dar tanto de forma impessoal, técnica e utilitária, como no caso do funcionário do metro que recebe treinamento para embarcar e desembarcar pessoas cegas; quanto pode evocar o caráter solidário, pessoal e relacional presente nas relações de cuidado, como é o caso do trocador de ônibus no relato de Camila. Com uma série de nuances entre estas duas modalidades. Cuidado e autonomia poderiam, assim, designar duas esferas da ação social no espaço público que, entre nós, foram traduzidas por 'casa' e 'rua' (DaMatta 1985). 
No cruzamento dos marcadores sociais de gênero e deficiência, a estrutura extremamente hierárquica da sociedade brasileira, fundada no código da família patriarcal e das mediações tradicionais, faz com que por vezes a moralidade da casa invada à rua exercendo, por meio das relações de ajuda, um controle social perverso dos movimentos de mulheres cegas nos seus deslocamentos urbanos que pode ter como efeito a sua imobilidade, seja no espaço da casa, seja no espaço da rua. A dominação é um atributo comum das relações de troca entre deficientes e não-deficientes que muitas vezes se exerce não tanto pelo que conscientemente se diz, mas pelo que inconscientemente se faz, pela dimensão da corporalidade, pela possibilidade de ir e vir, pelos fluxos, pelos ritmos ou a interrupção do movimento. Mesmo que em nome de um cuidado com o outro.

Como sugerem Nuremberg \& Mello (2012), a contribuição dos estudos feministas para os estudos sobre deficiência coloca o cuidado como responsabilidade do Estado e da sociedade, desnaturalizando uma visão desta atividade como naturalmente feminina. Uma ética do cuidado deve ser pautada nos direitos humanos, reconhecendo a deficiência como condição inerente à diversidade humana. No entanto, se a garantia do cuidado é fundamental para a manutenção da vida, pode não ser suficiente para garantir a qualidade do cuidado. Para pautar a ética do cuidado nos direitos humanos é necessário reconhecer plenamente o direito à autodeterminação das pessoas com deficiência, ou seja, a sua capacidade de escolha e autonomia. Para isso precisamos de uma noção alargada e corporificada de autonomia, não tanto aquela pautada na racionalidade do sujeito, mas uma que considere os modos corporais singulares de comunicação, interação e preferência na deficiência. Para Moser (2005), enquanto a realidade for construída com base no pressuposto de que existe um corpo universal e normal, corpos não padronizados sempre aparecerão como problemáticos e falharão em performatizar como 'mentes desincorporadas', a forma necessária de corporificação na normalização. 
Não é possível a igualdade, a autonomia ou a promoção da qualidade de vida na deficiência sem que haja a consideração de suas especificidades e diferenças, seja pela necessidade de alocação diferencial de recursos, na realização de mudanças estruturais que permitam a igualdade de acesso seja, talvez ainda mais fundamentalmente, pela transformação da perspectiva naturalizada de uma normalidade corporal como modo único ou principal de estar no mundo. Uma questão que pode ser definida como 'barreira atitudinal' que está na base da marginalização de pessoas com deficiência.

Penso ser possível ter outra experiência da relação entre deficiência e não deficiência que não fique na desigualdade (tanto a que se manifesta por meio da discriminação ou da denúncia, quanto na forma de pena ou caridade). Mas para isso é preciso que a transformação da normatividade que constrói subjetividades deficientes e não deficientes também se dê no nível visceral da experiência, já que estamos todos implicados nisso até o último fio de cabelo, como bem nos lembra Foucault (2010). Nós todos fomos constituídos e somos diariamente colonizados pela normalidade. Precisamos nos deixar afetar de outras maneiras pelas corporalidades distintamente constituídas da deficiência, construir novos afetos na relação para que novas realidades, novas formas de se relacionar com a singularidade dos corpos, possam se fazer existir.

A intenção, quando descrevo certas práticas e formas de saber-fazer da cegueira (von der Weid 2018) é abrir espaço para uma ontologia prática (Mol 2002), para um modo de ser na cegueira que não está dado na ordem das coisas, mas emerge de suas práticas sócio-materiais cotidianas, multiplicando, assim, os modos de estar no mundo - se a realidade é múltipla, as corporalidades também são. Ao abordar tais relações numa direção que problematiza nossos ideais corporificados de normalidade, acredito ser possível contribuir para alargar nosso imaginário sobre as diferentes formas de ser humano. Podemos desenvolver outra aproximação às relações entre deficiência e não deficiência se tratarmos uma lesão ou um impedimento (como olhos que 
não enxergam) não somente como um elemento que torna os corpos mais precários ou vulneráveis, mas também como um equipamento distintivo, que dota aquele que o possui de afecções e capacidades singulares. Nesta perspectiva os olhos que não enxergam não são considerados atributos que impedem ou inibem a vida, mas singularidades que são também forças generativas para a expressão da vida, capazes de nos oferecer outra perspectiva da vida.

Quando a ajuda considera as singularidades dos afetos e dos modos de existência corporal das pessoas envolvidas, ela também instaura novos agenciamentos e formas singulares de convivência nos espaços públicos. Seja nas políticas públicas ou nas relações ordinárias que estabelecemos com pessoas com deficiência nas ruas, devemos nos perguntar o quanto nossas formas de agir, nossa atitude e motivação quando oferecemos ajuda, por exemplo, e a própria maneira pela qual ela se concretiza, estão contribuindo para reproduzir formas hegemônicas e normativas de vida ou o quanto estamos abertos para agenciamentos que possam colaborar no cultivo de novas formas singulares de existência.

\section{Notas}

1 Sobre a passagem do modelo médico para o modelo social de deficiência e a crítica trazida pelas feministas ver Diniz (2007).

2 Por capacitismo (ableism) Campbell compreende "uma rede de crenças, processos e práticas que produzem um tipo particular de self e de corpo (o padrão corporal) que é projetado como perfeito, típico da espécie e, portanto, essencial e inteiramente humano. A deficiência é então moldada como um estado piorado de ser humano" (Campbell 2009:44).

3 O Instituto Benjamin Constant é um centro de referência nacional para questões da área de deficiência visual no Brasil e está localizado na cidade do Rio de Janeiro. Para maiores informações acessar: http://www.ibc.gov.br/.

4 Desde o início da pesquisa de campo, a experiência de se deslocar pelas ruas da cidade guiando pessoas cegas tem sido reveladora. Durante os deslocamentos se sobressaem tanto os aspectos materiais do ambiente que concorrem para a inacessibilidade urbana de pessoas cegas, quanto as estratégias empregadas para a técnica 
de 'guia vidente', as quais pude aperfeiçoar ao fazer o curso de especialização em técnico em Orientação e Mobilidade no IBC. Outros fatores como a proximidade corporal, nem sempre usual para pessoas desconhecidas, que está implicada na relação de ajuda, a experiência de movimento no deslocamento acoplado a outro corpo, além do risco de violação do espaço corporal e imposição de ajuda a que mulheres cegas estão sujeitas foram também elementos que a etnografia em movimento permitiu observar.

5 Priorizo no artigo o ponto de vista de pessoas cegas sobre as suas interações cotidianas com pessoas que enxergam na arena da rua e uma das razões para este recorte é o fato de, como sugere Scully (2010), a maior parte dos estudos sobre tais interações terem priorizado a perspectiva, as atitudes e os comportamentos de pessoas não deficientes. Esta é também uma das críticas feita por mulheres deficientes à teoria do cuidado (Morris 2001). Outro aspecto relevante levantado Scully (2010) é que, ao se priorizar o ponto de vista de grupos socialmente marginalizados seria possível desenvolver novos insights epistêmicos para certos aspectos das relações sociais que antes se considerava já definidos ou conhecidos. Nesta direção, acredito que a experiência localizada de pessoas cegas sobre as relações de ajuda no contexto urbano de uma cidade latino-americana como o Rio de Janeiro, com suas próprias topografias e códigos sociais para relacionar o público e o privado, podem trazer novas luzes sobre as noções de cuidado e autonomia que têm sido desenvolvidas a partir de um contexto anglo-saxão nas teorias do cuidado e nos estudos sobre deficiência.

6 Termo nativo utilizado para se referir às pessoas cegas que sabem desempenhar com destreza as técnicas de mobilidade com a bengala branca (ou bengala longa), dispositivo que auxilia a locomoção eficaz e segura de pessoas cegas.

7 Através deste experimento é possível levantar hipóteses sobre a variação na quantidade e nos tipos de ajuda necessária no deslocamento em função da interseccionalidade entre classe e deficiência. Quanto maiores as distâncias percorridas no cotidiano e quanto maior a variedade de meios de transporte utilizados para se chegar ao local de destino (van, Kombi, ônibus, metro, trem, mototáxi, etc.), mais recorrentes serão as ajudas. Dependendo da renda a pessoa pode optar pelo uso do transporte privado, como táxi ou aplicativos, evitando o desconforto da inacessibilidade dos ônibus. A renda mais elevada também permite escolher o local de moradia em função dos serviços disponíveis próximos à habitação, como supermercado, acesso ao metrô, bancos, etc. O grau de necessidade de ajuda parece então variar proporcionalmente à maior ou menor segregação sócio-espacial das pessoas. A partir dos dados do IBGE (2015) a respeito do cruzamento entre raça e pobreza, que mostram que em $201476 \%$ das pessoas entre os $10 \%$ com menores rendimentos eram pretas ou pardas, é possível inferir a sobreposição dos marcadores de raça, gênero, classe e deficiência para a segregação sócio-espacial urbana, a mobilidade e a recorrência da ajuda no deslocamento, embora não tenha sido possível aprofundar a discussão neste momento.

8 Sobre o efeito de objetificação ou despersonificação da pessoa cega nas relações de ajuda, o vídeo 'Cego não é uma pessoa, mas uma coisa...' do canal do youtube 'Cego em Ação', de Vanessa Bruna é eloquente: https://www.youtube.com/watch?$\mathrm{v}=\mathrm{m} 8 \mathrm{~s} 3$ gacaUks. 
9 Optei por priorizar as relações de ajuda que se estabelecem no cenário público da rua, mas pretendo, em outro momento, aprofundar a análise sobre cuidado, autonomia e dependência no âmbito das relações familiares de pessoas com deficiência visual.

10 'Atividades da Vida Diária' ou AVD é um atendimento que, junto com 'Braille', 'Orientação e Mobilidade', 'Escrita Cursiva' e 'Habilidades Básicas', compõe o ciclo básico do Programa de Reabilitação do Instituto Benjamin Constant.

\section{Referências}

BOURDIEU, Pierre. A Dominação Masculina. Rio de Janeiro: Bertrand Brasil.

BUTLER, Judith. 2015. Quadros de Guerra: Quando a vida é passivel de luto? Rio de Janeiro: Civilização Brasileira.

CAILlÉ, Alain. 2014. "Dádiva, care e saúde”. Sociologias, 16(36):42-59.

CAMPBELL, Fiona. 2009. Contours of Ableism: The production of disability and abledness. Nova Iorque: Palgrave Macmillan.

DAMATTA, Roberto. 1985. A Casa e a Rua. São Paulo: Brasiliense.

DELEUZE, G. \& GUATTARI, F. 1997. Mil Platôs: Capitalismo e esquizofrenia. Rio de. Janeiro, Editora 34.

DINIZ, Debora. 2007. O Que é Deficiência. São Paulo: Editora Brasiliense.

FOUCAULT, Michel. 2010. Os Anormais. São Paulo: Martins Fontes.

FRANCA, Tiago. 2014. Deficiência e Pobreza no Brasil. Tese de Doutorado. Coimbra: Universidade de Coimbra.

GOFFMAN, Erving. 1975. Estigma. Rio de Janeiro: Zahar.

1977. "The Arrangement between the sexes". Theory and Society, 4(3):301-331.

GUATTARI, F. \& ROLNIK, S. 1996. Micropolítica: Cartografias do desejo. Petrópolis: Vozes.

HUGHES, B. et al. 2005. "Love's Labours Lost? Feminism, the Disabled People's Movement and an Ethic of Care". Sociology, 39(2):259-275.

KEITH, Lois. 1996. "Encounters with strangers: The public's responses to disabled women and how this affects our sense of self". In MORRIS, J. (ed.): Encounters with Strangers: Feminism and disability, pp. 69-88. London: Women's Press.

KITTAY, Eva. 1999. Love's Labor: Essays in women, equality and dependency. New York: Routledge.

. 2011. "The ethics of care, dependence and disability". Ratio Juris, 24(1):49-58.

LEFÉBVRE, Henri. 1969. O Direito à Cidade. São Paulo: Documentos.

MAGNANI, José Guilherme. 2002. "De perto e de dentro". RBCS, 17(49):11-29. 
MARTINS, Bruno. 2006. "E se Eu Fosse Cego?": Narrativas silenciadas da deficiência. Porto: Edições Afrontamento.

MATURANA, H. \& VARELA, F. 1980. Autopoiesis and Cognition: The organization of the living. Boston: Reidel.

MOL, Annemarie. 2002. The Body Multiple: Ontology in medical practice. Durham: Duke University Press. . 2008. The Logic of Care. London: Routledge.

MORRIS, Jenny. 2001. "Impairment and Disability: constructing an ethics of care that promotes human rights". Hypatia, 16(4):1-16. . 2005. Citizenship and disabled people. (https://disability-studies.leeds.ac.uk/ wp-content/uploads/sites/40/library/morris-Citizenship-and-disabled-peoplefinal.pdf; acesso em 10/11/2018).

MOSER, Ingunn. 2005. "On becoming disabled and articulating alternatives: the multiple modes or ordering disability and their interferences". Cultural Studies, 19(6):667-700.

NICOLAU, S. et al. 2013. "Mulheres com deficiência e sua dupla vulnerabilidade". Ciênc. Saúde Coletiva, 18(3):863-872.

NUREMBERG, A. \& MELLO, A. 2012. "Gênero e Deficiência: interseções e perspectivas". Revista Estudos Feministas, 20(3):635-655.

OLIVER, Michael. 1990. The Politics of Disablement. London: Macmillan.

PAPERMAN, Patricia. 2013. "Émotions privées, émotions publiques". Multitudes, *(52):164-170.

PERLONGHER, Nestor. 2008. O Negócio do Michê. São Paulo: Fundação Perseu Abramo.

PIRES, Fatima L. 2016. "Discriminação na cidade: a mobilidade como direito social". Urbana, 8(1 [12]):95-120.

SASSAKI, R. K. 2007. "Nada sobre nós, sem nós: Da integração à inclusão". Revista Nacional de Reabilitação, 10(58):20-30.

SEEGER, A., DA MATTA, R. \& VIVEIROS DE CASTRO, E. 1979. “A construção da pessoa nas sociedades indígenas brasileiras". Boletim do Museu Nacional, 32:2-19.

SCULLY, Jackie. 2010. "Hidden labor: Disabled/Nondisabled encounters, agency, and autonomy". International Journal of Feminist Approaches to Bioethics, 3(2):25-42.

SHAKESPEARE, Tom. 2000. Help. Birmingham:Venture Press.

SILVA, Joseli Maria. 2007. "Gênero e sexualidade na análise do espaço urbano". Geosul, 22(44):117-134.

SILVERS, Anita. 1995. "Reconciling equality to difference: caring (F)or justice for people with disabilities". Hypatia, 10 (1):30-55.

TRONTO, Joan. 1999. Moral Boundaries: A political argument for an ethic of care. London: Routledge. 
VON DER WEID, Olivia. 2018. "Corporalidades cegas como formas de saberfazer”. In CASTRO, R., ENGEL, C. \& MARTINS, R. (eds.): Antropologia, Saúde e Contextos de Crise, pp. 174-192. Brasília: Sobrescrita.

WINANCE, Myriam. 2016. "Rethinking disability: lessons from the past, questions for the future". ALTER - European Journal of Disability Research, 10(2):99-110.

WINANCE, M., DAMAMME, A. \& FILLION, E. 2015. "Thinking the aid and care relationship from the standpoint of disability: stakes and ambiguities". ALTER - European Journal of Disability Research, 9(3):163-168.

\begin{abstract}
This article reflects on the exchange relationships established during the daily urban displacement of blind people from the imperative of help, with special attention to the crossing between gender and disability. Starting from the account of blind people about their experiences of being helped, especially in the street scenario, I evaluate the conditions of the exchange relationship that is established in this type of encounters. The reflection places ethnographic situations in dialogue with the way the help dimension has been seen by care studies and disability studies. Without losing sight from the notions of care, dependence and autonomy that nurture the debate between these studies, I propose a look at how the localized dimension of help is capable of articulating different ways of acting and thinking about disability.
\end{abstract}

Keywords: Disability, Blindness, Urban Mobility, Gender, Care.

Recebido em outubro de 2018.

Aprovado em dezembro de 2018. 